\title{
Case Report: Hepatopulmonary syndrome as the first clinical manifestation of cirrhosis in a patient with underlying chronic lung disease [version 1; peer review: 1 not approved]
}

Charles Murphy (D), Danit Arad

Internal Medicine, Montefiore Medical Center, Bronx, Bronx, NY, 10029, USA
V1 First published: 02 Aug 2018, 7:1175

https://doi.org/10.12688/f1000research.15434.1

Latest published: 16 May 2019, 7:1175

https://doi.org/10.12688/f1000research.15434.2

\section{Abstract}

An 86 year old woman with multiple chronic lung diseases (including chronic obstructive pulmonary disease, bronchiectasis, and untreated mycobacterium avium-intracellulare) presented with two weeks of increased shortness of breath, notably worse when seated as compared to when lying down. After treatments focused on her known conditions did not resolve her dyspnea, the differential diagnosis was broadened and she was found to have cirrhosis. As a result of this new diagnosis, transthoracic echocardiography and arterial blood gas analysis were performed and together yielded the diagnosis of hepatopulmonary syndrome. We describe a rare presentation of hepatopulmonary syndrome manifesting as a patient's first clinical evidence of cirrhosis, a diagnosis made difficult by this patient's numerous other lung diseases which muddied the picture.

\section{Keywords}

Hepatopulmonary Syndrome, COPD, MAI Infection, Bronchiectasis

\author{
Open Peer Review \\ Approval Status \\ 12 \\ 23 \\ version 2 \\ (revision) \\ 16 May 2019

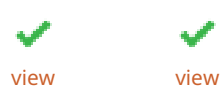 \\ version 1 \\ 02 Aug 2018 \\ 1. Robert Rodríguez-Roisin, University of \\ Barcelona, Barcelona, Spain \\ 2. Mohan Rudrappa ID, Mercy Hospital, Joplin, \\ USA \\ 3. Elias Kouroumalis (iD), University of Crete, \\ Heraklion, Greece
}

Any reports and responses or comments on the article can be found at the end of the article. 
Corresponding author: Danit Arad (Danit.Arad@gmail.com)

Author roles: Murphy C: Conceptualization, Investigation, Writing - Original Draft Preparation, Writing - Review \& Editing; Arad D: Conceptualization, Supervision, Writing - Review \& Editing

Competing interests: No competing interests were disclosed.

Grant information: The author(s) declared that no grants were involved in supporting this work.

Copyright: @ 2018 Murphy C and Arad D. This is an open access article distributed under the terms of the Creative Commons Attribution License, which permits unrestricted use, distribution, and reproduction in any medium, provided the original work is properly cited.

How to cite this article: Murphy $C$ and Arad D. Case Report: Hepatopulmonary syndrome as the first clinical manifestation of cirrhosis in a patient with underlying chronic lung disease [version 1; peer review: 1 not approved] F1000Research 2018, 7:1175 https://doi.org/10.12688/f1000research.15434.1

First published: 02 Aug 2018, 7:1175 https://doi.org/10.12688/f1000research.15434.1 


\section{Introduction}

The triad of chronic liver disease, hypoxemia, and microvascular dilatations/malformations in the lungs make up hepatopulmonary syndrome (HPS), a well-known sequela of hepatic cirrhosis ${ }^{1}$. These aforementioned vascular abnormalities result in intrapulmonary shunting, which yields the clinical findings of dyspnea (universally) as well as digital clubbing and/or cyanosis (both very common) $)^{2}$. We report a case of a patient presenting with HPS as their first clinical manifestation of cirrhosis, and describe how it was distinguishable from other potential causes of her symptoms such as her comorbid chronic obstructive pulmonary disease (COPD), bronchiectasis, and mycobacterium avium-intracellulare (MAI) infection.

\section{Case report}

An 86 year old retired latina woman with a past medical history of COPD, bronchiectasis, MAI infection (not previously treated), diabetes mellitus, hyperlipidemia, and hypertension presented with two weeks of worsened dyspnea and nonproductive cough. She reported a baseline of daily shortness of breath with an exercise tolerance of 3 blocks, but over the two weeks prior to her presentation it decreased to the point where she would feel dyspneic when walking around her apartment. Interestingly she stated that she also generally felt more short of breath while seated than when lying down, and also cited a worsening cough over this time course productive of green sputum. Her exam on presentation was significant for an oral temperature of 101.4 degrees Fahrenheit, oxygen saturation of $84 \%$ on room air, tachypnea and coarse crackles appreciated diffusely on lung examination. Her blood-work was notable for a white blood cell count of $19.8 \mathrm{k} / \mu \mathrm{L}$, with multiple diffuse small nodular opacities seen on chest $\mathrm{x}$-ray. She was started on levofloxacin for treatment of a presumed bronchiectasis flare along with oxygen therapy via nasal cannula in addition to other supportive treatments. Although her fever, leukocytosis, and cough improved with antibiotics (further supporting a diagnosis of bronchiectasis flare), her dyspnea and hypoxemia persisted. Consequently, a chest computerized tomography (CT) scan was ordered which showed the same extensive nodularities seen on chest x-ray, but also elucidated a nodular liver consistent with cirrhosis. While her platelet count, transaminases, bilirubin, and prothrombin time were all normal and she had no ascites or other edema on exam, she did however have spider angiomas. Further chart review done at that time revealed that she had known cirrhotic characteristics on liver imaging as they were incidentally seen almost five years prior, although she had never had any decompensations or serologic evidence of liver dysfunction since then. Work-up back then elucidated no potential cause except for non-alcoholic fatty liver disease, given her histories of hyperlipidemia and diabetes. In light of this knowledge gained from deep chart review, the specter of hepatopulmonary syndrome was raised as a possible explanation for her persistent hypoxemia and dyspnea. In order to investigate this possibility, both seated and supine arterial blood gases were obtained which elucidated orthodeoxia (see Table 1). A transthoracic echocardiogram with bubble study was then performed which showed an intrapulmonary shunt (see Figure 1), thereby confirming the diagnosis of HPS. While oxygen supplementation caused her dyspnea to improve and oxygen saturation to rise to a safe level,
Table 1. Patient's orthodeoxia as established via arterial blood gas analysis.

\begin{tabular}{l|l|l|}
\hline Parameter & Supine & Seated \\
\hline $\mathrm{FiO}_{2}$ & $21 \%$ (Room Air) & $21 \%$ (Room Air) \\
\hline $\mathrm{PaO}_{2}$, Arterial & $65.5 \mathrm{mmHg}$ & $53.1 \mathrm{mmHg}$ \\
\hline Direct O2 Saturation & $93.3 \%$ & $88.6 \%$ \\
\hline $\begin{array}{l}\mathrm{FiO}_{2}-\text { Fraction of inspired oxygen, } \mathrm{PaO}_{2}-\text { Partial pressure arterial } \\
\text { oxygen. }\end{array}$
\end{tabular}

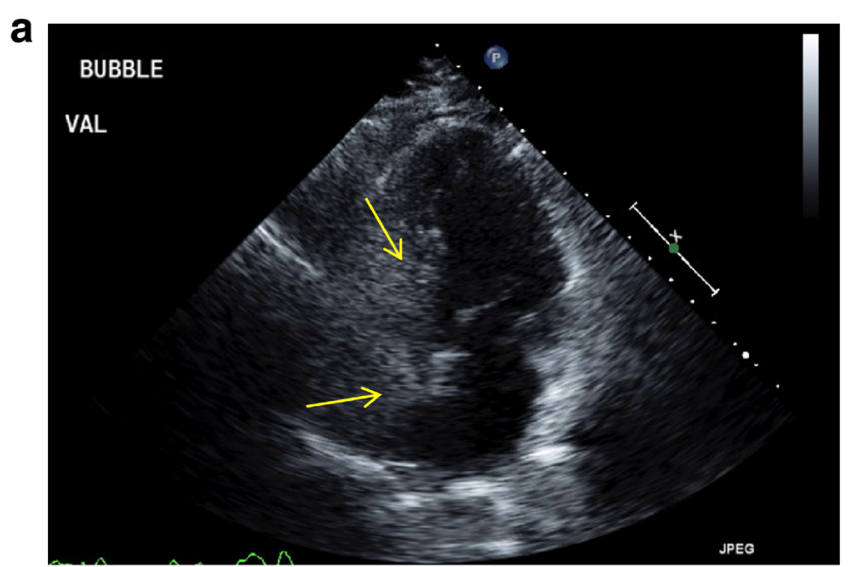

b

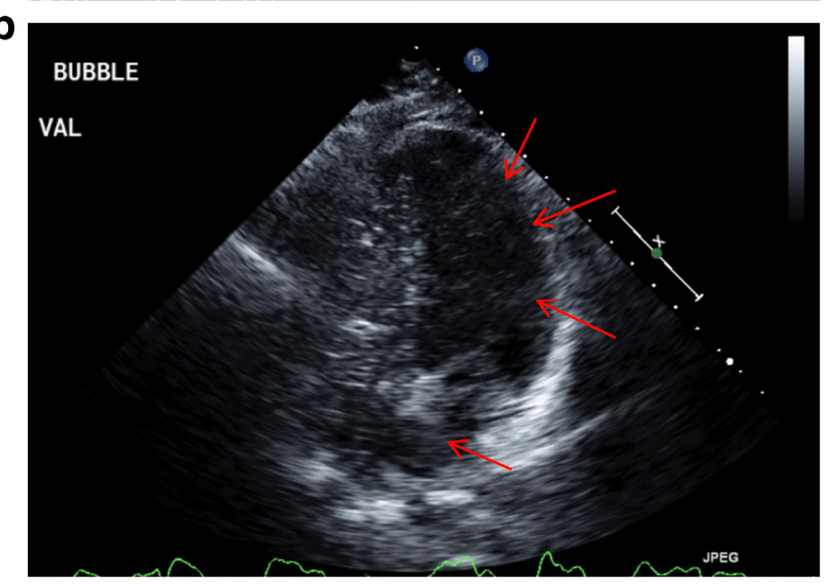

Figure 1. Still images from patient's transthoracic echocardiogram showing (a) no early shunting with saline bubble (identified by yellow arrows) injection, followed by (b) late passage of bubbles (identified by red arrows) into the Left Atrium and Ventricle representing Intrapulmonary Shunting.

she interestingly was never able to reach a saturation of $100 \%$. However given this improvement in her dyspnea and oxygenation, as well as the resolution of all signs and manifestations of the bronchiectasis flare that she initially presented with, the patient was discharged home with oxygen. Soon after discharge, she was seen in a pulmonology clinic where treatment for MAI was commenced. When last seen a month afterward, the patient reported that she was tolerating her treatments well and felt improved since her hospital discharge. 


\section{Discussion}

Our patient possessed all three of the cardinal findings of hepatopulmonary syndrome: chronic liver disease, hypoxemia, and microvascular dilatations/malformations in the lungs. Her symptom of platypnea (shortness of breath worsened by going from a supine to seated position) and finding of orthodeoxia on arterial blood gas analysis also clearly pointed to HPS. But while most cirrhotic patients with hepatopulonary syndrome have only mild disease and its severity is typically proportional to that of their cirrhosis, she presented with severe disease despite having seemingly compensated cirrhosis ${ }^{3}$. Moreover, it is very unusual for HPS to be the first symptomatically manifesting sequela of cirrhosis as it was in this patient; there are few other examples of this happening in the literature ${ }^{4}$.

As it is classically described, our patient's intrapulmonary vascular abnormalities resulted in intrapulmonary shunting, which yielded her dyspnea and hypoxemia. More specifically, this shunting caused her to have platypnea, which is the symptomatic manifestation of orthodeoxia, and has been shown to be very closely tied with HPS. In one prospective study comparing cirrhotics with HPS vs. those without the complication, platypnea was endorsed by $65.5 \%$ of the HPS group vs $6.2 \%$ of the non-HPS cirrhotic group 5 .

Given that they are also manifestations of cirrhosis-related vascular malformations, spider angiomas are also commonly seen in HPS as they were with our patient ${ }^{6}$. The intrapulmonary anomalies can be reliably detected via saline-enhanced transthoracic echocardiography, as well as with more advanced confirmatory tests such as technitium-99m macroaggregated albumin (MAA) nuclear scanning or pulmonary angiography ${ }^{3,7,8}$. Given the overwhelming presence of intrapulmonary shunting seen on her transthoracic echocardiogram though, these more advanced and expensive tests were not pursued in our patient's case.

Once the diagnosis is made with the aforementioned triad, disease severity is assessed via $\mathrm{PaO}_{2}$. Patients with mild disease have a $\mathrm{PaO}_{2} \geq 80 \mathrm{mmHg}$, those with moderate have $\mathrm{PaO}_{2} \geq 60<80 \mathrm{mmHg}$, severe have $\mathrm{PaO}_{2} \geq 50<60 \mathrm{mmHg}$, and those with very severe disease have a $\mathrm{PaO}_{2}$ of $<50 \mathrm{mmHg}^{9}$. Our patient was found to have severe disease based upon her $\mathrm{PaO}_{2}$. The pathogenesis is thought to involve increased serum levels of nitric oxide (although correlations with elevated carbon monoxide and tumor necrosis factor $\alpha$ have also been seen) resulting from cirrhosis, which is postulated to cause pulmonary vascular dilatation and arteriovenous malformations (AVMs) $)^{7,10}$. Autopsy studies have shown that the number of dilated precapillary and capillary vessels in the lungs far outnumbers the number of pulmonary AVMs in these patients, but the end result of each is the same: passage of mixed-venous blood into the pulmonary veins, resulting in shunting, V/Q mismatch, and hypoxemia ${ }^{7}$. Where those vessels dilated as a result of HPS are concerned, the shunting is a result of diffusion-limited gas exchange. Cirrhosis itself (independent of HPS) is also associated with impaired autoregulation of pulmonary vascular tone, and this coupled with the shunting seen in hepatopulmonary syndrome is what is thought to cause orthodeoxia: as gravitational changes in pulmonary blood distribution cannot be accommodated for, there is increased blood supply to the lung bases, where the amount of ventilation relative to perfusion is less than that of the superior lung zones ${ }^{7,11}$.

The only definitive treatment for HPS is liver transplantation ${ }^{12}$. While those with HPS are more prone to post-operative complications than other patients post-liver transplant, ultimately those who survive have resolution of the hypoxemia caused by their pre-transplant $\mathrm{HPS}^{13}$. Given her age, comorbidities, and otherwise well-compensated cirrhosis, liver transplant was not considered in our patient.

In addition to HPS, there are other similar clinical entities which are worth discussing as part of the differential diagnosis for patients who present like ours. Similar to HPS, portopulmonary hypertension (PPH) is also a sequela of cirrhosis which is characterized by pulmonary hypertension (as defined by elevated mean arterial pressure of $>25 \mathrm{mmHg}$ at rest, and pulmonary vascular resistance greater than 240 dynes $/ \mathrm{sec} / \mathrm{cm}^{-5}$ ) in the setting of portal hypertension and/or cirrhosis with other causes of PH having been excluded ${ }^{9}$. Patients with PPH typically present with clinical findings consistent with other causes of pulmonary hypertension, namely external dyspnea, fatigue, chest pain, and/or syncope, with progression to cor pulmonale in severe cases $^{14}$. PPH was excluded in our patient by the fact that her transthoracic echocardiogram showed no evidence of pulmonary hypertension.

Hereditary hemorrhagic telangiectasia (HHT) is a genetic (autosomal dominant) disease in which arteriovenous malformations (AVMs) and mucocutaneous telangiectasis form throughout the body ${ }^{15}$. The predominant symptom with which people present is paroxysmal epistaxis related to AVMs in the nasal mucosa, although $15-35 \%$ of patients with HHT have pulmonary AVMs which cause dyspnea in a manner analogous to those with HPS $^{16}$.

While it was tempting at first to presume that our patient's untreated MAI (and/or her other lung diseases, see Table 2 below) could be causing her symptoms, the clinical presentations which result from this infection are not mimickers of HPS. Those with symptomatic pulmonary MAI infection typically present in one of two ways, depending on whether they have underlying lung disease or not. Those with underlying lung disease (most commonly COPD or bronchiectasis) typically have a tuberculosis-like (albeit milder) presentation: chronic cough, weakness, malaise, weight loss, dyspnea, and upper-lobe predominant infiltrates and/or cavitation on chest imaging ${ }^{17}$. Patients with underlying bronchiectasis will usually have their MAI infection develop in bronchiectatic areas, not necessarily in the upper lobes $^{18}$. Those without underlying lung disease tend to present with months of productive cough, without the other "tuberculosis-like" constitutional symptoms ${ }^{19}$. A subset of these patients classically present with "Lady Windermere syndrome:" lingular/ right-middle lobe infiltrates in elderly women without predisposing lung disease who suppress their cough ${ }^{20}$. Regardless of which way a patient presents, diagnosis is made via the combination 
Table 2. Comparing notable clinical and diagnostic characteristics of her different lung disorders.

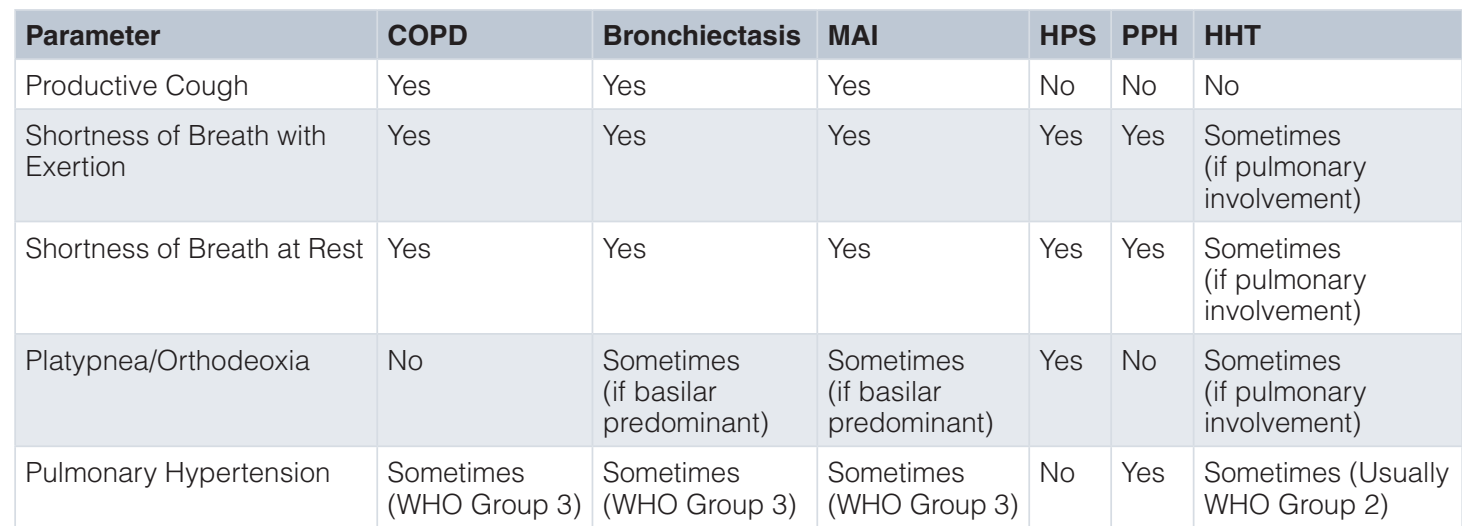

COPD- Chronic obstructive pulmonary disease, MAI - mycobacterium avium-intracellulare infection, HPS - Hepatopulmonary syndrome, $\mathrm{PPH}$ - Portopulmonary hypertension, HHT - Hereditary hemorrhagic telangiectasia, WHO - World Health Organization.

of radiographic findings indicative of pulmonary disease along with either MAI-positive sputum or an MAI-positive bronchial wash in a patient with respiratory symptoms, according to the Infectious Disease Society of America and the American Thoracic Society $^{21}$.

Hepatopulmonary syndrome belongs on the differential diagnosis for dyspnea in any patient with chronic liver disease, even those with previously compensated cirrhosis like our patient. While it can present in a way which is symptomatically similar to that of other chronic lung diseases, it can be definitively diagnosed via a relatively simple work-up which should be performed in any dyspneic patient with cirrhosis. While the only definitive cure is liver transplant, it can be conservatively managed via oxygen therapy when transplant is contraindicated, as it was in our patient's interesting case.

\section{Consent}

Written informed consent for publication of their clinical details and/or clinical images was obtained from the patient.

\section{Data availability}

All data underlying the results are available as part of the article and no additional source data are required.

\section{Competing interests}

No competing interests were disclosed.

Grant information

The author(s) declared that no grants were involved in supporting this work.
1. Ho V: Current concepts in the management of hepatopulmonary syndrome. Vasc Health Risk Manag. 2008; 4(5): 1035-1041. PubMed Abstract | Publisher Full Text | Free Full Text

2. Mohammad Alizadeh AH, Fatemi SR, Mirzaee V, et al.: Clinical features of hepatopulmonary syndrome in cirrhotic patients. World J Gastroenterol. 2006; 12(12): 1954-1956.

PubMed Abstract | Publisher Full Text | Free Full Text

3. Fragaki M, Sifaki-pistolla D, Samonakis DN, et al.: Screening for Hepatopulmonary Syndrome in Cirrhotic Patients Using Technetium 99mmacroaggregated Albumin Perfusion Lung Scan (Tc-MAA): Diagnostic Approach and Clinical Correlations. J Clin Gastroenterol. 2017. PubMed Abstract | Publisher Full Text

4. Zieliński M, Hartleb M, Sitek P, et al.: Dyspnoea, cyanosis and digital clubbing in a 28-year-old patient as a result of hepatopulmonary syndrome. Adv Respir Med. 2017; 85(6): 339-344.

PubMed Abstract | Publisher Full Text

5. Younis I, Sarwar S, Butt Z, et al.: Clinical characteristics, predictors, and survival among patients with hepatopulmonary syndrome. Ann Hepatol. 2015; 14(3): 354-60.

PubMed Abstract
6. Silvério Ade O, Guimarães DC, Elias LF, et al:: Are the spider angiomas skin markers of hepatopulmonary syndrome? Arq Gastroenterol. 2013; 50(3): 175-179.

PubMed Abstract | Publisher Full Text

7. Rodríguez-Roisin R, Krowka MJ: Hepatopulmonary syndrome--a liver-induced lung vascular disorder. N Engl J Med. 2008; 358(22): 2378-2387. PubMed Abstract | Publisher Full Text

8. Offer J, Green L, Houghton AR, et al.: A case of hepatopulmonary syndrome. Echo Res Pract. 2015; 2(2): K25-K27.

PubMed Abstract | Publisher Full Text | Free Full Text

9. Rodríguez-roisin R, Krowka MJ, Hervé $\mathrm{P}$, et al.: Pulmonary-Hepatic vascular Disorders (PHD). Eur Respir J. 2004; 24(5): 861-80. PubMed Abstract | Publisher Full Text

10. Cremona G, Higenbottam TW, Mayoral V, et al:: Elevated exhaled nitric oxide in patients with hepatopulmonary syndrome. Eur Respir J. 1995; 8(11): 1883-1885.

PubMed Abstract | Publisher Full Text

11. Gómez FP, Martínez-Pallí G, Barberà JA, et al:: Gas exchange mechanism of orthodeoxia in hepatopulmonary syndrome. Hepatology. 2004; 40(3): 660-6. PubMed Abstract | Publisher Full Text 
12. Rodriguez-Roisin R, Krowka MJ: Is severe arterial hypoxaemia due to hepatic disease an indication for liver transplantation? A new therapeutic approach. Eur Respir J. 1994; 7(5): 839-842.

PubMed Abstract

13. Eriksson LS, Soderman C, Ericzon BG, et al.: Normalization of ventilation/ perfusion relationships after liver transplantation in patients with decompensated cirrhosis: evidence for a hepatopulmonary syndrome. Hepatology. 1990; 12(6): 1350-1357. PubMed Abstract | Publisher Full Text

14. Hoeper MM, Krowka MJ, Strassburg CP: Portopulmonary hypertension and hepatopulmonary syndrome. Lancet. 2004; 363(9419): 1461-8. PubMed Abstract | Publisher Full Text

15. Sharathkumar AA, Shapiro A: Hereditary haemorrhagic telangiectasia. Haemophilia. 2008; 14(6): 1269-80.

PubMed Abstract | Publisher Full Text

16. Krynytska I, Marushchak M, Mikolenko A, et al:: Differential diagnosis of hepatopulmonary syndrome (HPS): Portopulmonary hypertension (PPH) and hereditary hemorrhagic telangiectasia (HHT). Bosn J Basic Med Sci. 2017; 17(4): 276-285.

PubMed Abstract | Publisher Full Text | Free Full Text
17. Teirstein AS, Damsker B, Kirschner PA, et al.: Pulmonary infection with Mycobacterium avium-intracellulare: diagnosis, clinical patterns, treatment. $M$ Sinai J Med. 1990; 57(4): 209-15.

PubMed Abstract

18. Kilby JM, Gilligan PH, Yankaskas JR, et al:: Nontuberculous mycobacteria in adult patients with cystic fibrosis. Chest. 1992; 102(1): 70-5. PubMed Abstract | Publisher Full Text

19. Prince DS, Peterson DD, Steiner RM, et al:: Infection with Mycobacterium avium complex in patients without predisposing conditions. N Engl J Med. 1989; 321(13): 863-8.

PubMed Abstract | Publisher Full Text

20. Reich JM, Johnson RE: Mycobacterium avium complex pulmonary disease presenting as an isolated lingular or middle lobe pattern. The Lady Windermere syndrome. Chest. 1992; 101(6): 1605-9.

PubMed Abstract | Publisher Full Text

21. Griffith DE, Aksamit T, Brown-Elliott BA, et al.: An official ATS/IDSA statement: diagnosis, treatment, and prevention of nontuberculous mycobacterial diseases. Am J Respir Crit Care Med. 2007; 175(4): 367-416.

PubMed Abstract | Publisher Full Text 


\section{Open Peer Review}

\section{Current Peer Review Status: $\mathrm{X}$}

Version 1

Reviewer Report 29 August 2018

https://doi.org/10.5256/f1000research.16819.r37169

(C) 2018 Rodríguez-Roisin R. This is an open access peer review report distributed under the terms of the Creative Commons Attribution License, which permits unrestricted use, distribution, and reproduction in any medium, provided the original work is properly cited.

\section{Robert Rodríguez-Roisin}

Pneumology Service, Thorax Institute, Hospital Clinic-The August Pi i Sunyer Biomedical Research Institute (IDIBAPS)-Networked Centre for Biomedical Research on Respiratory Diseases (CIBERES) (Hospital Clínic-IDIBAPS-CIBERES), University of Barcelona, Barcelona, Spain

This is another case report of an interesting and complex HPS in the context of several comorbidities, such as COPD and bronchiectasis, let alone the coexistence of MAI infection, that each, all in combination or even one more than another entity, can cause arterial hypoxaemia, along with an incomplete differential diagnosis approach. All in all both the discussion and presentation are weak and modest which detract from the potential clinical interest of the case report. Behind this negative short review lie three major caveats.

First, the lack of a better knowledge on gas exchange abnormalities in HPS is overwhelming despite that some of the quoted references (i.e., ref 7) masterly describe the pathophysiology of gas exchange alterations in HPS. Yet, the Authors miss a succinct good description. One of the reasons of this is that the Author is confounded by the use of the broad term of 'shunting' to encompass the three well established intrapulmonary determinants of arterial hypoxaemia in HPS (ventilation-perfusion imbalance, increased intrapulmonary shunt, and diffusion limitation to $\mathrm{O} 2$ transfer) quite thoroughly reported in a recent publication of the Amer Physiol Soc (RodriguezRoisin R, et al. ${ }^{1}$ ). May I therefore suggest to the Author to take a look at this publication and make the appropriate changes in your paper. HPS is not a problem of 'intrapulmonary shunting', as it is repeatedly quoted, but a predominant ventilation-perfusion mismatching along with other additional altered pulmonary and non-pulmonary determinants of gas exchange (see also, Rodriguez-Roisin ${ }^{2}$ ).

Second, the Author does not afford the lung function testing of this lady, including the most likely smoking habits of his old patient which are completely ignored. As a result, we are in the middle of nowhere to grasp the comprehensive nature of her gas exchange abnormalities. Are these due to her severe chronic pulmonary problems (COPD with bronchiectasis), to HPS as the author is inclined to, without providing any rationale, or to a combination of both pulmonary and liver disorders (most likely). The lack of a proper differential diagnosis is another of the main gaps. I, for 
me, suggest to also read a very interesting paper focusing on cardiopulmonary comorbidities and HPS (Martinez GP, et al. ${ }^{3}$ ) that may help the Author to improve his differential diagnosis. Moreover, the Author has completely neglected the relevant role of the alveolar-arterial oxygen partial pressure difference. With due respect, I suggest you read again ref 7, now more critically and more in detail!

Third, I have to admit that although it is most likely that the arterial hypoxaemia of this old lady is due to a combination of lung and hepatic problems, there is a sentence in the Case Report that worries me. It says: 'Soon after discharge, she was seen in a pulmonology clinic where treatment for MAI was commenced. When last seen a month afterward, the patient reported that she was tolerating her treatments well and felt improved since her hospital discharge'. This sentence makes me suspicious and questions me if the hypoxaemia is due to HPS for there are no pharmacological options for HPS so far.

\section{References}

1. Rodríguez-Roisin R, Krowka MJ, Agustí A: Hepatopulmonary Disorders: Gas Exchange and Vascular Manifestations in Chronic Liver Disease.Compr Physiol. 2018; 8 (2): 711-729 PubMed Abstract | Publisher Full Text

2. Rodriguez-Roisin R: Nonpulmonary influences on gas exchange.Compr Physiol. 2014; 4 (4): 145594 PubMed Abstract | Publisher Full Text

3. Martinez G, Barberà JA, Navasa M, Roca J, et al.: Hepatopulmonary syndrome associated with cardiorespiratory disease.J Hepatol. 1999; 30 (5): 882-9 PubMed Abstract

Is the background of the case's history and progression described in sufficient detail? No

Are enough details provided of any physical examination and diagnostic tests, treatment given and outcomes?

No

Is sufficient discussion included of the importance of the findings and their relevance to future understanding of disease processes, diagnosis or treatment?

No

Is the case presented with sufficient detail to be useful for other practitioners? No

Competing Interests: No competing interests were disclosed.

Reviewer Expertise: COPD and hepatic vascular disorders

I confirm that I have read this submission and believe that I have an appropriate level of expertise to state that I do not consider it to be of an acceptable scientific standard, for reasons outlined above. 
The benefits of publishing with F1000Research:

- Your article is published within days, with no editorial bias

- You can publish traditional articles, null/negative results, case reports, data notes and more

- The peer review process is transparent and collaborative

- Your article is indexed in PubMed after passing peer review

- Dedicated customer support at every stage

For pre-submission enquiries, contact research@f1000.com 